\title{
Hydrodynamic Modelling, Thermodynamic and Textural Variations during Common Beans Soaking
}

\author{
E. M. Kwofie, O. I. Mba, M. Ngadi* \\ Department of Bioresource Engineering, McGill University, Québec, Canada \\ Email: ^michael.ngadi@mcgill.ca
}

How to cite this paper: Kwofie, E.M., Mba, O.I. and Ngadi, M. (2019) Hydrodynamic Modelling, Thermodynamic and Textural Variations during Common Beans Soaking. Advances in Chemical Engineering and Science, 9, 27-43.

https://doi.org/10.4236/aces.2019.91003

Received: September 26, 2018

Accepted: January 1, 2019

Published: January 4, 2019

Copyright $\odot 2019$ by authors and Scientific Research Publishing Inc. This work is licensed under the Creative Commons Attribution International License (CC BY 4.0).

http://creativecommons.org/licenses/by/4.0/

\begin{abstract}
Hydrodynamic characteristics and its associated thermodynamic and textural variation of three common Malawian beans varieties (Boma, Sugar and Mandondo) during soaking were evaluated at four temperature regimes $\left(25^{\circ} \mathrm{C}, 35^{\circ} \mathrm{C}, 45^{\circ} \mathrm{C}\right.$ and $\left.55^{\circ} \mathrm{C}\right)$. The equilibrium water uptake of $127 \% \pm 5 \%$ was reached in 10,6 , and 4 hours respectively, for $25^{\circ} \mathrm{C}, 35^{\circ} \mathrm{C}$ and $45^{\circ} \mathrm{C}$. Not much variation was observed between $45^{\circ} \mathrm{C}$ and $55^{\circ} \mathrm{C}$ except for sugar beans where equilibrium water uptake was reached within two hours of soaking at $55^{\circ} \mathrm{C}$. Three models namely Peleg, two-parameter Mitscherlich model and viscoelastic model were used to evaluate the comparative predicting capabilities of the bean hydrodynamic characteristics. All models predicted the water absorption accurately $\left(R^{2}>0.903\right.$, RMSE $\left.<4.95\right)$. In addition, the viscoelastic model gave a good prediction for the two water absorption phases. The impact of temperature and time on moisture transfer rate and bean hardness showed the activation kinetic parameters to be between 25 - $65 \mathrm{~kJ} / \mathrm{mol}$. Sugar beans were found to be the least hard. At room temperature, its hardness reduced by $58 \%$ within 2 hours of soaking. At higher temperature $\left(55^{\circ} \mathrm{C}\right)$ hardness values were reduced to $12.5 \%, 11.1 \%$ and $15.0 \%$ within the first hour for Boma, Sugar and Mandondo beans, respectively.
\end{abstract}

\section{Keywords}

Common Beans, Soaking, Thermodynamics, Kinetics, Bean Hardness

\section{Introduction}

Common beans (Phaseolus vulgaris) are included in pulses that make a significant contribution to human and animal food supply. Globally, bean legumes make important contribution to the diets and nutrition. They are known to be 
important sources of starch and fibre, minerals and bioactive compounds and health benefits [1] [2]. Soaking of common beans is an important pre-process method of producing edible beans both locally and commercially. This process occurs either at room temperature or with water at higher temperatures but below the starch gelatinization temperature prior to cooking at much higher temperatures.

Water uptake during soaking influences the product's textural and nutritional qualities [3] [4] [5]. Hence, its modeling has been given significant attention. Several researchers have employed different hydrodynamic models to evaluate the water uptake or absorption during soaking. The Peleg model [6] is the most widely used model for hydrodynamics. It has been employed on different food products including chickpea [7] [8], mung grain [9], dry bean [10] [11], lentils [12].

Although, the hydrodynamics of beans has been considered as a diffusion process, and the liquid water transport has been modeled using Fick's law, other researchers [9] have argued that the liquid water movement cannot be described as solely diffusional mechanism. This is because the Fick's law hinges on assumptions that are partially valid for hydration processes. Several other hydrodynamic models have been evaluated for bean soaking. For instance, Shafaei and Masoumi [13] evaluated the moisture absorption kinetics of three Iranian bean varieties using fourteen standard models and concluded that the Weibull equation fitted best. Wood and Harden [7] also evaluated the hydration and swelling properties of chickpea using four different models including the modified Peleg model and their proposed two-parameter Mitscherlich model. They concluded that the two-parameter Mitscherlich model was superior due to its simplicity and the ability to allow individual curves to be overlaid for ease of comparison. Several studies [14] [15] [16] [17] have showed that water absorption kinetics of agro-products such as grains and cereals occurs in two phases-a rapid early phase and much slower second phase which continues until product equilibration. Some researchers [18] have argued that the inability of popular models such as the Peleg, Fick or Weibull to evaluate the water absorption rate during the second phase of absorption requires modification in water absorption modeling. They proposed a new model which uses the time-dependent behavior found in creep test of viscoelastic materials to model water uptake in the two phases.

Therefore, the objectives of this work were to 1) model the hydrodynamic characteristics of three Malawian bean varieties using the Peleg, the two-parameter Mitscherlich model and the recently proposed viscoelastic two-phase model; 2) evaluate the thermodynamics variations during soaking of common beans; 3 ) assess the textural changes during soaking.

\section{Materials and Methods}

\subsection{Materials}

Three varieties of common beans namely Boma, Sugar and Mandondo harvested 
from the Kameme and Lufita communities in the Chitipa district of Malawi were used for this work. The beans were harvested during the 2016 harvest season. Prior to the experiments, the seeds were cleaned by removing foreign materials such as dried pods, stones, dirt, and broken bean seeds. Seeds with length $10.5 \pm$ $0.5 \mathrm{~mm}$ were used in this work for consistency and to eliminate the influence of seed size on water absorption. Initial moisture content of samples was determined using the ASAE S352.2 DEC 97.

\subsection{Hydrodynamic Experiments}

Hydrodynamic experiments were conducted using randomly selected seeds of each variety to obtain $4 \pm 0.1 \mathrm{~g}$. The seeds were soaked in $20 \mathrm{ml}$ distilled water at different temperatures $\left(25^{\circ} \mathrm{C}, 35^{\circ} \mathrm{C}, 45^{\circ} \mathrm{C}\right.$ and $\left.55^{\circ} \mathrm{C}\right)$. The selected temperatures were below the starch gelatinization temperature. Prior to the experiment, the distilled water and its container were maintained at the desired temperature. For temperatures above room temperature, a water bath was used to establish the thermal equilibrium. Soaking were than for 15, 30, 60, 120, 240, 360, 480, 600, and $720 \mathrm{~min}$. Preliminary experiments showed negligible water absorption variations after $600 \mathrm{~min}$. At the end of each experimental run, the water was drained and the surface water on the samples dried using a paper towel. The weight of the samples was then determined. Experiments were conducted in triplicates.

The water absorption capacity was evaluated using Equation (1) [10] [19]

$$
W_{a}=\frac{W_{f}-W_{i}}{W_{i}} \times 100
$$

where $W_{a}$ is the water absorption (d.b. \%), $W_{f}$ is the final weight of seeds after soaking $(\mathrm{g})$ and $W_{i}$ is the initial weight of seeds prior to soaking $(\mathrm{g})$.

\subsection{Chemical Properties}

The Dumas combustion method in accordance with AOAC method 968.06 [20] was used to determine the total nitrogen content of bean powders. The crude protein was then estimated using a conversion factor of 6.25. Moisture content of pulverized samples was measured using the hot air oven method AOAC Method 925.09 [20]. Crude fat was determined by petroleum ether extraction method (AOAC method 963.15) using automated solvent extractor (VelpScientific, Usmate, Italy). The energy value (in kilojoules) of the bean seeds was estimated by multiplying the values of protein (\%), fat (\%) and carbohydrate (\%) by the factors $16.7,37.7$ and 16.7 , respectively [21].

\subsection{Hydrodynamic Modeling}

Hydrodynamics of legumes have widely been modelled with theoretical and empirical models. Due to the relative ease of use, the latter is preferred. The Peleg equation and its modifications are the most used empirical models for hydrodynamic characteristics. In this work, in addition to the Peleg model, three other hydrodynamic models namely viscoelastic model, the Weibull model and the 
two-parameter Mitscherlich model were all fitted to the experimental data.

\subsubsection{Peleg Model}

The Peleg model [6] is a two parameter sorption equation used to predict water adsorption of rice during soaking. Rate of water absorption is defined as:

$$
R=\frac{\mathrm{d} M}{\mathrm{~d} t}=\frac{K_{1}}{\left(K_{1}+K_{2} t\right)^{2}}
$$

In its linearized form, the water absorption capacity is given by Equation (3)

$$
\frac{t}{M_{t}-M_{o}}=K_{1}+K_{2} t
$$

where, $t$ is the soaking time in $\min , M_{t}$ is the moisture content (d.b) at time $t$ (\%), $M_{o}$ is the initial moisture content (d.b), $K_{1}$ is the Peleg rate constant, $\min / \%$ m.c. (d.b), and $K_{2}$ is the Peleg capacity constant 1/\% m.c. (d.b).

The equilibrium moisture content, $M_{e}$ (d.b) was determined using Equation (4) [22] given by:

$$
M_{e}=M_{o}+\frac{1}{K_{2}}
$$

\subsubsection{Viscoelastic Model}

The viscoelastic model is based on the fact that water absorption characteristics are time dependent just like other viscoelastic properties of food. Therefore, the two-phase water absorption characteristics of common beans can be model using Equation (5)

$$
M_{t}-M_{o}=M_{r e t}\left(1-e^{-t / T_{r e l}}\right)+K_{r e l} t
$$

where $K_{r e l}$ is the rate of water absorption in the relaxation phase (\%/min.), $M_{r e t}$ is the total retarded moisture content and $T_{r e t}$ is the retardation time, referring to the time required by the seed moisture content to reach $63 \%$ of $M_{\text {ret }}$.

\subsubsection{Two Parameter Mitscherlich Model}

The Mitscherlich model [23] is an asymptotic regression model given by

$$
W_{t}=\gamma-\alpha \beta^{t}
$$

where, $W_{t}$ is the weight after soaking for time $t$ (hours), $\gamma$ is the asymptote, $\alpha$ is the increase in weight and $\beta$ is a curve parameter related to the rate of weight change over the period $t=0$ to $t=\infty$.

In its modified form, the weight gain is modeled and the asymptote, $\gamma$ is eliminated. The water absorption capacity can now be predicted with a two parameter Mitscherlich model given by Equation (7) [7] [12]:

$$
W_{a}=\alpha\left(1-\beta^{t}\right)
$$

where, $W_{a}$ is the water absorption (d.b \%) after soaking for $\mathrm{t}(\mathrm{min})$.

\subsubsection{Model Evaluation}

The models were evaluated using the coefficient of determination $\left(R^{2}\right)$ and the 
root mean square error (RMSE). The expression for estimation of the $R^{2}$ and RMSE are given by Equation (8) and Equation (9) as:

$$
\begin{gathered}
R^{2}=\frac{\sum_{i=1}^{n}\left(M_{\text {exp }, i}-M_{\text {exp }, \mathrm{ave}}\right)^{2}-\sum_{i=1}^{n}\left(M_{\mathrm{exp}, i}-M_{p r e, \mathrm{i}}\right)^{2}}{\sum_{i=1}^{n}\left(M_{\text {exp }, i}-M_{\text {exp }, \mathrm{ave}}\right)^{2}} \\
\mathrm{RMSE}=\sqrt{\frac{\sum_{i=1}^{n}\left(M_{\mathrm{exp}, i}-M_{p r e, i}\right)^{2}}{N}}
\end{gathered}
$$

\subsection{Thermodynamic Variations}

Thermodynamic variations during soaking can be determined by estimating the dependence of the Peleg model coefficient on the water temperature. This dependence is expressed in the Arrhenius equation shown in Equation (10):

$$
\frac{1}{K}=K_{r e f, f} \exp \left[-\frac{E_{a}}{R}\left(\frac{1}{T}-\frac{1}{T_{r e f}}\right)\right]
$$

where, $K_{\text {ref }}$, is the coefficient of hydration at reference temperature; $E_{a}$ is the activation energy expressed in $\mathrm{KJmol}^{-1} ; R$, is the universal gas constant (8.314 $\left.\mathrm{KJmol}^{-1} \cdot \mathrm{K}^{-1}\right) ; T$, the experimental temperature $(K)$ and $T_{\text {ref }}$ is the reference temperature $(K)$. The reference temperature was chosen as the average of the experimental temperatures to lessen the co-linearity of $K_{\text {ref }}$ and activation energy [10] [24]. In the linearized form Equation (10) becomes:

$$
\ln \left(\frac{1}{K}\right)=\ln K_{r e f, f}+\left(\frac{E_{a}}{R}\right)\left(\frac{1}{T}-\frac{1}{T_{r e f}}\right)
$$

A plot of $\ln \left(\frac{1}{K}\right)$ against $\left(\frac{1}{T}-\frac{1}{T_{\text {ref }}}\right)$ gives a linear graph with $\left(\frac{E_{a}}{R}\right)$ as slope. The activation energy $E_{a}$ is then determined form the slope. From the estimated $E_{a}$ other thermodynamics parameters can be determined. The enthalpy, entropy and Gibbs free energy of activation can be estimated from Equations (12)-(14), respectively [10] [25].

$$
\begin{gathered}
H=E_{a}-R T \\
\Delta S=R\left(\ln K_{r e f}-\ln \frac{K_{B}}{h_{p}}-\ln T\right) \\
\Delta G=\Delta H-T \Delta S
\end{gathered}
$$

where, $R$ is the universal gas constant; $\ln K_{\text {ref }}$ is the ordinate intersection of the linearized plot to obtain the activation energy (Equation (11)) KB is the Boltzmann constant $\left(1.38 \times 10^{-23} \mathrm{~J} \cdot \mathrm{K}^{-1}\right) ; h_{p}$, is the Planck's constant $\left(6.626 \times 10^{-34} \mathrm{~J} \cdot \mathrm{s}\right)$; and $T$ is the absolute temperature.

\subsection{Texture Changes during Soaking}

Changes in hardness of dry and soaked beans (as a function of time and temper- 
ature) were determined using a TA-HD Plus texture analyzer (Stable Micro Systems Ltd, Surrey, UK), a return-to-start (RTS), measuring force under compression using a 2-mm cylindrical stain less-steel probe (P2). The selected probe is widely used for bean hardness due to its ability to impact the tegument which helps differentiate similar samples [26]. A 50-kg load cell was used for the experiment. Soaked beans were compressed axially to $75 \%$ of their original height applying a cross head speed of $1.0 \mathrm{~mm} / \mathrm{s}$ and a pre-test and post-test speed of 1 $\mathrm{mm} / \mathrm{s}$ [27].

Bean hardness was defined as the peak force of the texture curve corresponding to the required force to deform the seed. Due to significant variation of individual bean hardness [24] ten (10) bean seeds were chosen to represent each treatment. For consistency, the orientations of the seeds on the analyzer platform were kept uniform.

\section{Results and Discussions}

\subsection{Chemical Properties}

The chemical composition of the varieties used in the study is shown in Table 1. The average protein, fat and carbohydrate contents of all samples were 25.8, 1.34 and $60.01 \%$, respectively. The gross energy varied between 1474 and $1499 \mathrm{~kJ} / 100$ g. Analysis of variance of among the different chemical components shows that only the protein content was significantly different $(\mathrm{p}<0.01)$ among the selected cultivars. However, a mean comparison using Tukey-Kramer HSD show protein content of Boma beans and Mandondo were not significantly different ( $\mathrm{p}>$ 0.05). Sugar beans on the other hand were significantly higher than the other beans $(\mathrm{p}<0.01)$. The protein content $(24.1 \%-28.7 \%)$ of the selected varieties was similar to those reported by Joshi, Adhikari [12]. They were however, higher than some common beans powders reported in the literature [28] [29] and other legumes such as chickpeas, peas [29] and lentils but lower than others like Faba beans [30].

\subsection{Hydrodynamic Characteristics}

Figure 1 shows a plot of the hydrodynamic characteristics of the studied cultivars at different soaking times and water temperature. It can be seen from these plots that water uptake was faster in the initial stages (first $240 \mathrm{~min}$.) for all temperatures. Although, it has been demonstrated by other researchers [31] [32]

Table 1. Chemical composition of common beans.

\begin{tabular}{ccccccc}
\hline $\begin{array}{c}\text { Sample } \\
\text { Name }\end{array}$ & $\begin{array}{c}\text { Protein } \\
(\%)\end{array}$ & $\begin{array}{c}\text { Ash } \\
(\%)\end{array}$ & $\begin{array}{c}\text { Moisture } \\
(\%)\end{array}$ & $\begin{array}{c}\text { Fat } \\
(\%)\end{array}$ & $\begin{array}{c}\text { Carbohydrate Gross Energy } \\
(\%)\end{array}$ & \begin{tabular}{c} 
(kJ/100 g) \\
\hline Boma
\end{tabular} \\
$24.81 \pm 0.69$ & $3.55 \pm 0.32$ & $9.89 \pm 0.01$ & $1.53 \pm 0.00$ & 60.22 & 1477.68 \\
Sugar beans & $27.67 \pm 0.99$ & $3.21 \pm 0.15$ & $8.55 \pm 0.08$ & $1.21 \pm 0.00$ & 59.36 & 1499.02 \\
Mandondo & $24.91 \pm 0.32$ & $3.04 \pm 0.12$ & $10.30 \pm 0.01$ & $1.29 \pm 0.00$ & 60.46 & 1474.31 \\
\hline
\end{tabular}

Source: Authors' experimental results 


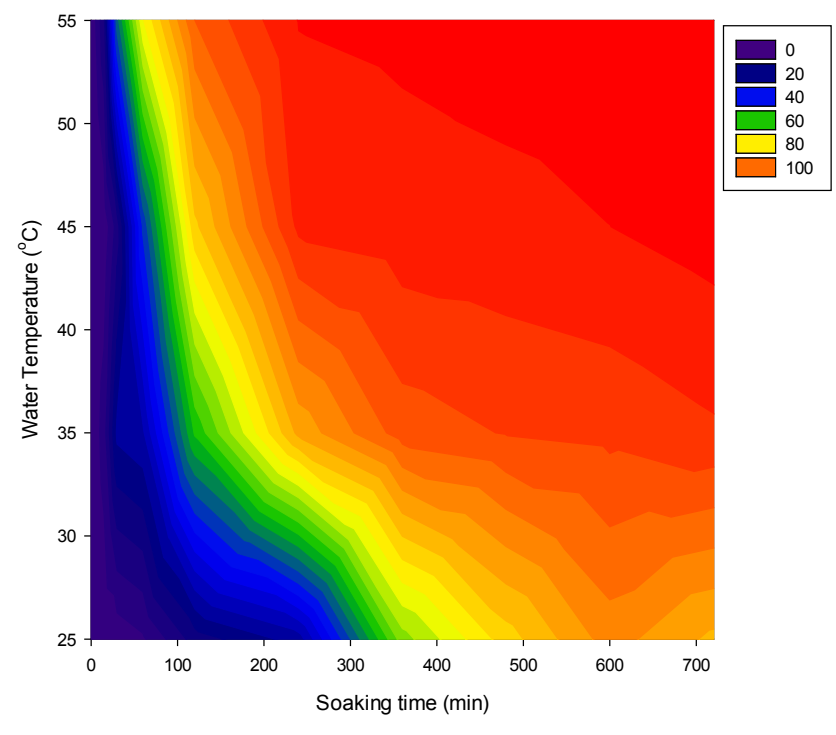

(a)

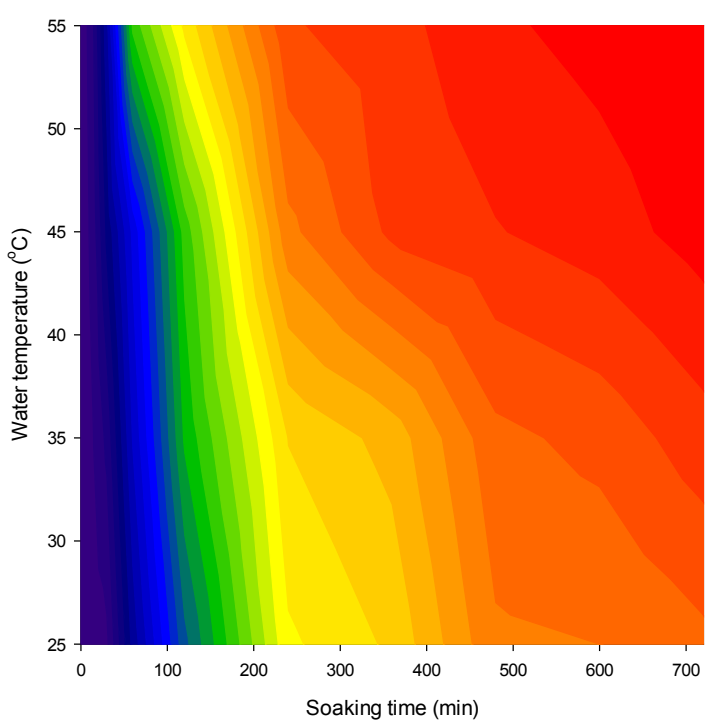

(b)

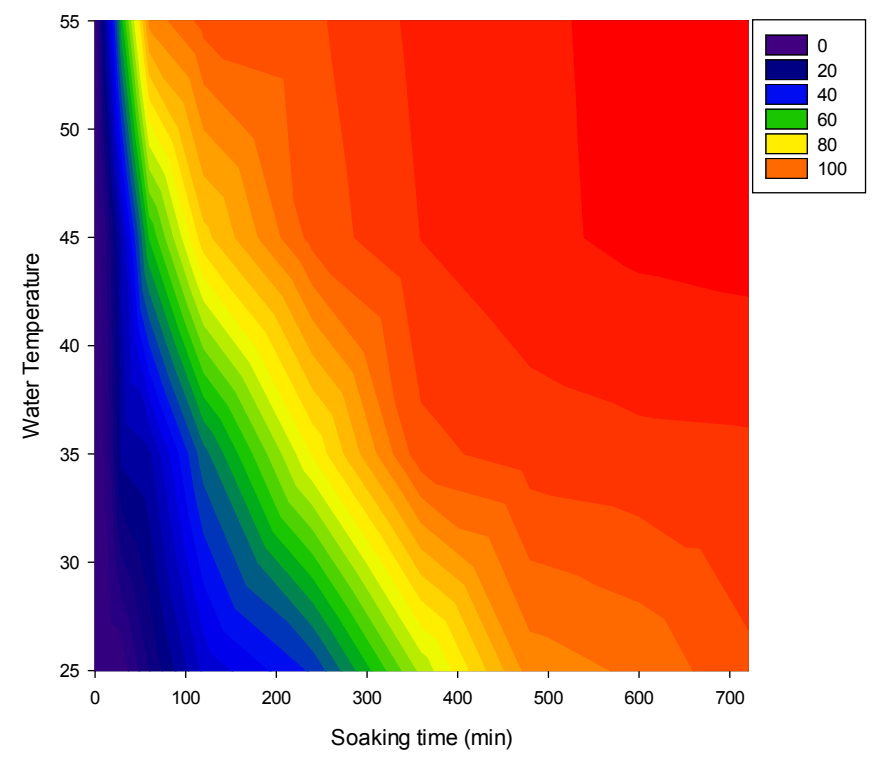

(c)

Figure 1. Contour plots of water uptake during soaking at different water temperature (a) Boma beans (b) Sugar beans and (c) Mandondo beans.

that the main mechanism controlling the rate of water absorption in seeds is diffusion through the endosperm regardless of the process condition. During hydration, water is absorbed by the seed coat, then diffused into the interior and cotyledon [33]. It was evident from the results obtained that the influence of temperature was substantial. For instance, after soaking Boma beans for four hours at room temperature, only $21.8 \%$ water uptake was recorded compared to $89.2 \%$ when soaked at $35^{\circ} \mathrm{C}$. Certainly, the rate of hydration increases with rising temperature which may be attributed to the changes in resistance to gain diffusion. Several studies [32] [34] [35] have supported the argument that a significant shortening of the processing time is the result of accelerating the water ab- 
sorption with higher temperature.

The effect of variety on water absorption can be seen by comparing the plots. Hydrodynamic behavior of Sugar beans differs significantly from Boma and Mandondo beans. It showed even a much faster water uptake within the first 200 mins of soaking.

The results also showed that equilibrium water uptake was similar for all varieties even at different temperatures, however, the time to reach that point varied significantly for different soaking water temperature. This may be attributed to the increase in water permeability as the temperature rises. On the average, the equilibrium water uptake was reached in 10,6 , and 4 hours, respectively for water temperature at $25^{\circ} \mathrm{C}, 35^{\circ} \mathrm{C}$ and $45^{\circ} \mathrm{C}$. Not much variation was seen between $45^{\circ} \mathrm{C}$ and $55^{\circ} \mathrm{C}$ except for sugar beans where equilibrium water uptake was reached within two hours of soaking at $55^{\circ} \mathrm{C}$.

\subsection{Hydrodynamic Modeling}

\subsubsection{Peleg Model}

The experimental data were fitted to the Peleg model (Equation (3)). Using a non-linear regression analysis, the model constants were determined and presented in Table 2. As shown in the table, the model constant associated the water transfer rate, $K_{1}$ decreased as water temperature increased for all varieties. The rate constant is inversely related to the initial water absorption hence a lower value for $K_{1}$ implies a higher water absorption rate. For a temperature rise from $25^{\circ} \mathrm{C}-55^{\circ} \mathrm{C}, K_{1}$ varied from $5.006-0.706,3.884-0.390$ and $1.829-0.669$, respectively, for Boma, Sugar and Mandondo varieties. The $K_{1}$ results of the three varieties were statistically not significant from each other $(\mathrm{P}<0.05)$ at temperatures higher than $35^{\circ} \mathrm{C}$. Turhan, Sayar [22] also observed similar results

Table 2. Model parameters of the Peleg rate and capacity constants.

\begin{tabular}{cccccc}
\hline Variety & Temperature & $K_{1}(\mathrm{~min} / \% \mathrm{MC}(\mathrm{d} . \mathrm{b})$ & $K_{2}(\mathrm{~min} / \% \mathrm{MC}(\mathrm{d} . \mathrm{b})$ & $R^{2}$ & RMSE \\
\hline Boma Beans & 25 & 5.006 & 0.034 & 0.903 & 3.15 \\
& 35 & 2.619 & 0.031 & 0.999 & 0.25 \\
& 45 & 0.982 & 0.030 & 0.997 & 0.36 \\
Sugar Beans & 55 & 0.706 & 0.029 & 0.996 & 0.43 \\
& 25 & 3.844 & 0.035 & 0.945 & 2.40 \\
& 35 & 1.832 & 0.033 & 0.979 & 1.39 \\
& 45 & 0.580 & 0.031 & 0.997 & 0.44 \\
& 55 & 0.390 & 0.029 & 0.997 & 0.46 \\
Mandondo beans & 25 & 1.829 & 0.032 & 0.979 & 1.28 \\
& 35 & 1.665 & 0.031 & 0.983 & 1.30 \\
& 45 & 1.368 & 0.028 & 0.981 & 1.16 \\
& 55 & 0.669 & 0.027 & 0.996 & 0.55 \\
\hline
\end{tabular}

$K_{1}$ is the Peleg rate constant and $K_{2}$ is the Peleg capacity constant. 
at temperatures above $40^{\circ} \mathrm{C}$. Several factors including temperature, soaking duration, presence and concentration of salt have been attributed to higher mass flow rates during soaking [10] [36] [37]. Higher temperature results in increased mass transfer due to the partial gelatinization of the endosperm and subsequent softening and expansion of seed. This results in the opening of more pores and cracks hence faster water transmission through seeds. Beside soaking conditions (temperature and time) other inherent seed characteristics such as cell wall structure, seed composition and compactness of cells in the seeds have been mentioned as contributing to higher rate of transfer [18] [38].

Similarly, $K_{2}$ which represents the maximum water absorption capacity followed a decreasing trend as water temperature increased. This was expected due to the inverse relationship with the water absorption capacity as reported by other researchers [22]. There was no statistical significant difference among the varieties studied, implying that the maximum water holding capacity of the varieties were the same even at different temperatures provided there was sufficient time to reach equilibrium water uptake. Depending on the food material under consideration and whether soluble solids loss have been considered in the evaluation, the water absorption capacity of a food material may increase or decrease with temperature. In this study, soluble solid loss had not been considered hence the observed trend.

\subsubsection{Two Parameter Mitscherlich Model}

The two parameter Mitscherlich model was fitted to the experimental data and the results displayed in Table 3 . The result indicates the Maximum hydration parameter, $\alpha$ increase with increasing temperature for all the studied varieties. The rate of hydration represented as $\beta$, on the other hand decrease with increasing temperature.

In contrast to raw experimental data which indicated that regardless of the soaking temperature, the equilibrium water uptake was similar for all varieties, the two parameter Mitscherlich model showed that the maximum hydration among the varieties at room temperature, $\alpha$ differs significantly $(\mathrm{p}<0.05)$. This may be due to an underestimation of maximum hydration at lower temperature. This is also reflected in the high RMSE values at room temperature.

\subsubsection{Viscoelastic Model}

Table 4 shows result of non-linear regression analysis of fitting the viscoelastic model to the experimental data. The results show that the viscoelastic model accurately predicted the hydrodynamic characteristics of the selected common bean varieties with RMSE of less than 2.5. Additionally, both the rapid early water absorption and the slower second phases were adequately described by the model parameters. The amount of water absorbed in the first phase increased with increasing hydration temperature for all varieties as expected. Mandondo beans showed the highest first phase water absorption of $99.5 \%$ at $55^{\circ} \mathrm{C}$ while Boma bean showed the lowest initial water absorption (49.2\%) at room temperature. The time to reach this initial phase varied from 128 to $178 \mathrm{~min}$ at room 
Table 3. Two parameter Mitscherlich model parameter estimation and goodness of fit.

\begin{tabular}{cccccc}
\hline Variety & Temperature & $\alpha$ & $\beta$ & $R^{2}$ & RMSE \\
\hline Boma beans & 25 & 102.5 & 0.999 & 0.945 & 2.53 \\
& 35 & 110.8 & 0.994 & 0.991 & 1.88 \\
Sugar beans & 45 & 115.9 & 0.992 & 0.972 & 2.25 \\
& 55 & 117.2 & 0.984 & 0.988 & 4.52 \\
& 25 & 104.7 & 0.995 & 0.985 & 4.91 \\
& 35 & 108.1 & 0.989 & 0.990 & 4.21 \\
& 45 & 110.5 & 0.985 & 0.995 & 3.19 \\
Mandondo & 55 & 111.4 & 0.976 & 0.987 & 4.39 \\
& 25 & 109.0 & 0.996 & 0.987 & 4.78 \\
& 35 & 111.1 & 0.994 & 0.992 & 3.77 \\
& 45 & 117.5 & 0.993 & 0.995 & 3.15 \\
& 55 & 119.4 & 0.990 & 0.990 & 4.57 \\
\hline
\end{tabular}

Table 4. Viscoelastic parameter estimation and goodness of fit.

\begin{tabular}{cccccccc}
\hline Variety & Temperature & $M_{o} \%(\mathrm{~d} . \mathrm{b})$ & $M_{\text {rel }} \%(\mathrm{~d} . \mathrm{b})$ & $T_{\text {rel }} \min$ & $K_{\text {rel }} \%(\mathrm{~d} . \mathrm{b}) / \mathrm{min}$ & $R^{2}$ & $\mathrm{RMSE}$ \\
\hline Boma Beans & 25 & 9.96 & 49.2 & 177.94 & 0.029 & 0.987 & 2.420 \\
& 35 & 9.96 & 74.5 & 145.99 & 0.025 & 0.966 & 0.551 \\
& 45 & 9.96 & 82.6 & 102.15 & 0.010 & 0.984 & 0.527 \\
Sugar Beans & 55 & 9.96 & 90.3 & 55.40 & 0.005 & 0.991 & 0.123 \\
& 25 & 10.21 & 58.1 & 128.21 & 0.107 & 0.976 & 1.660 \\
& 35 & 10.21 & 75.8 & 91.32 & 0.030 & 0.986 & 0.988 \\
& 45 & 10.21 & 81.2 & 39.01 & 0.013 & 0.989 & 0.368 \\
& 55 & 10.21 & 85.6 & 22.29 & 0.012 & 0.989 & 0.120 \\
Mandondo Beans & 25 & 9.69 & 62.1 & 149.45 & 0.029 & 0.994 & 0.490 \\
& 35 & 9.69 & 75.0 & 137.93 & 0.019 & 0.990 & 0.679 \\
& 45 & 9.69 & 80.3 & 109.69 & 0.011 & 0.979 & 0.274 \\
& 55 & 9.69 & 99.5 & 50.25 & 0.004 & 0.987 & 0.201 \\
\hline
\end{tabular}

temperature. At higher temperature $\left(55^{\circ} \mathrm{C}\right)$ this time reduced to a third for $B o$ ma and Mandondo beans and only $17 \%$ for Sugar beans. This implies commercial hydration process for sugar beans can be achieved rapidly (less than 25 mins) during processing by increasing water temperature to $55^{\circ} \mathrm{C}$.

\subsubsection{Model Comparison}

A comparison of the three models used for this work is shown in Figure 2. As can be seen from the plots, all models accurately described the water absorption characteristics of the common bean varieties at the selected soaking temperatures $\left(25^{\circ} \mathrm{C}-55^{\circ} \mathrm{C}\right)$. However, the Peleg model seems to better predict the hydration 


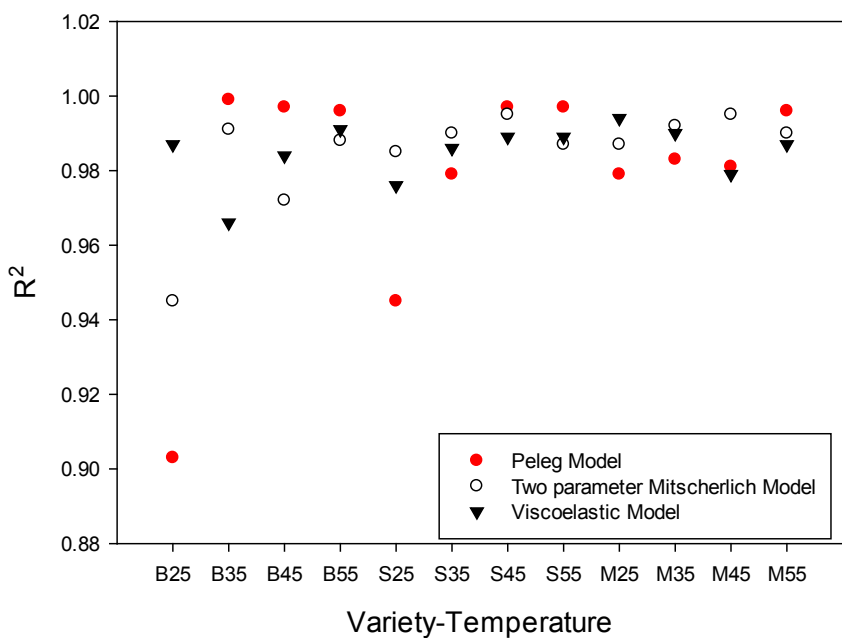

(a)

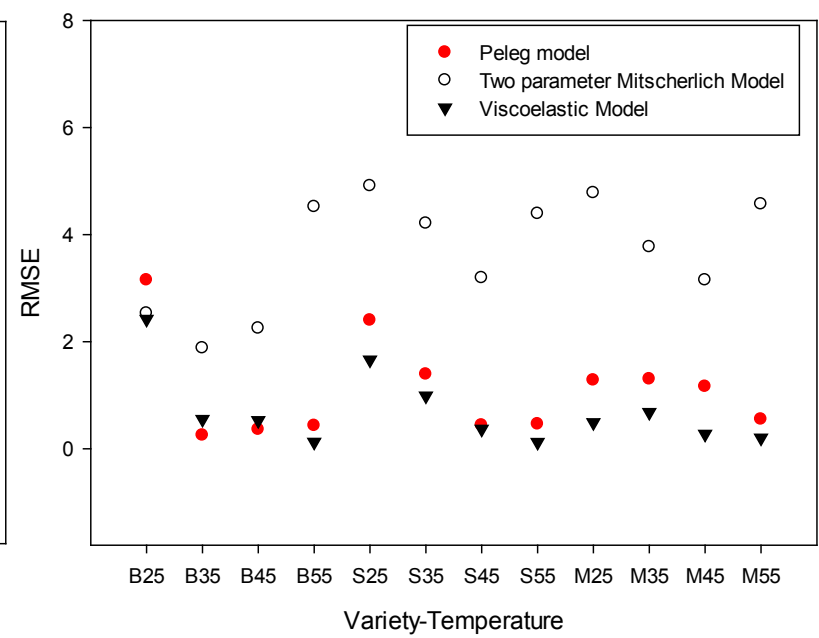

(b)

Figure 2. Comparison of the three-selected model (a) $R^{2}$ (b) RMSE (B represent Boma beans, S represent Sugar beans and M represent Mandondo beans).

behavior of Boma beans than others, while the Viscoelastic model predict Mandondo beans better than the others.

\subsection{Thermodynamic Variations}

Temperature dependence of the initial rate of water absorption has been modeled with the Arrhenius equation expressed in Equation (10). The kinetic parameters are reported in the Table 5 below. The magnitude of the activation ener$\mathrm{gyE}_{\mathrm{a}}$, was within the range of values typical of grains and legumes, $11.1-136.5$ $\mathrm{kJ} / \mathrm{mol}$ [22] [39].

Changes in thermodynamic properties during common bean hydration are displayed in Figure 3. The result reveals that the enthalpy and entropy change decreased with increasing temperature, but the Gibbs free energy showed a positive correlation with temperature. Sugar beans had the maximum change in enthalpy and entropy at all the experimental temperatures and the lowest Gibbs free energy among the varieties studied. The enthalpy which is the heat dissipated by the hydration process at constant pressure is the binding energy or intermolecular force established between both the solvent and the adsorbent surface as well as the solvent and the absorbed molecules. Therefore, with the relatively high activation energy of the Sugar beans the enthalpy change shown in Figure 3(a) can be expected. This change demonstrated the measure of energy variation taking place because of water molecules and bean interaction during hydration.

\subsection{Effect of Soaking Time and Temperature on Bean Texture during Soaking}

Textural variations determined as the changes in bean hardness as a function of time and temperature are shown in Figure 4 and Figure 5. Three phases of 


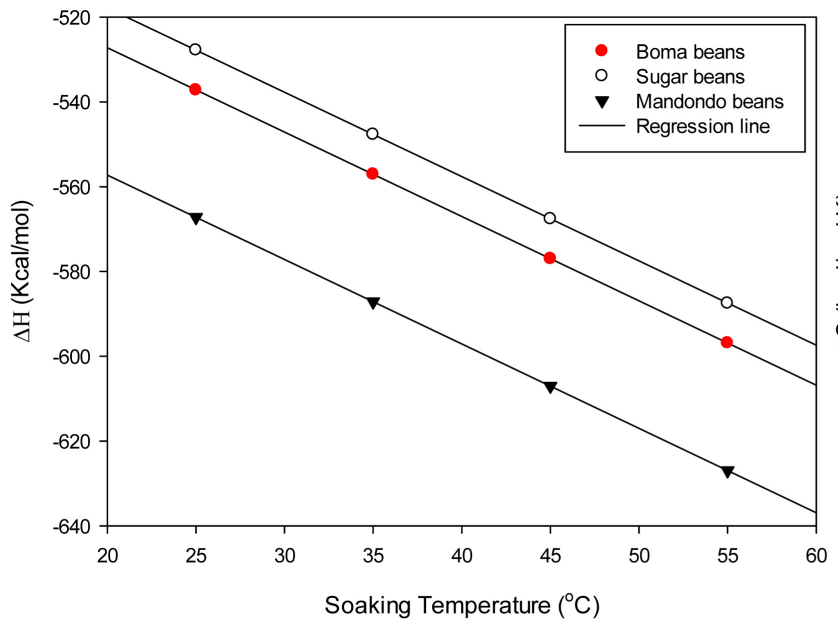

(a)

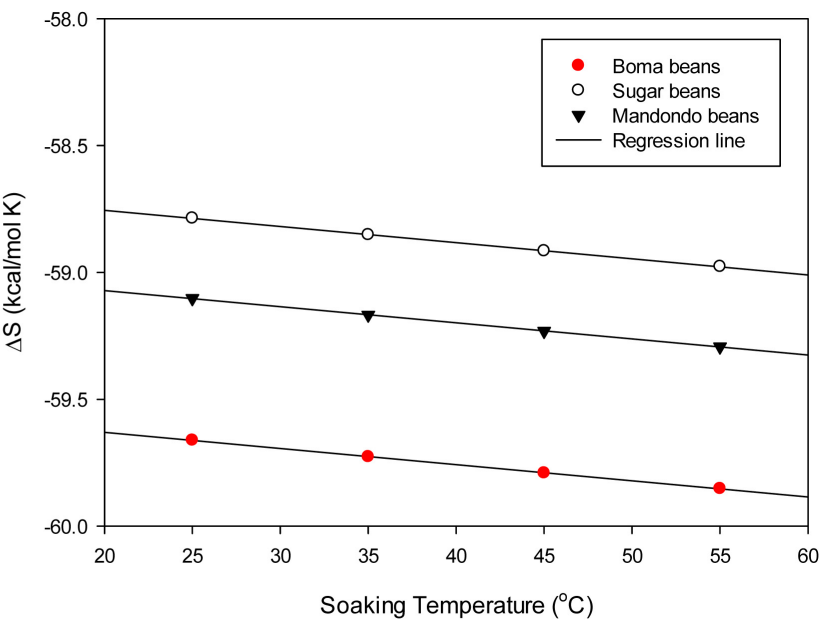

(b)

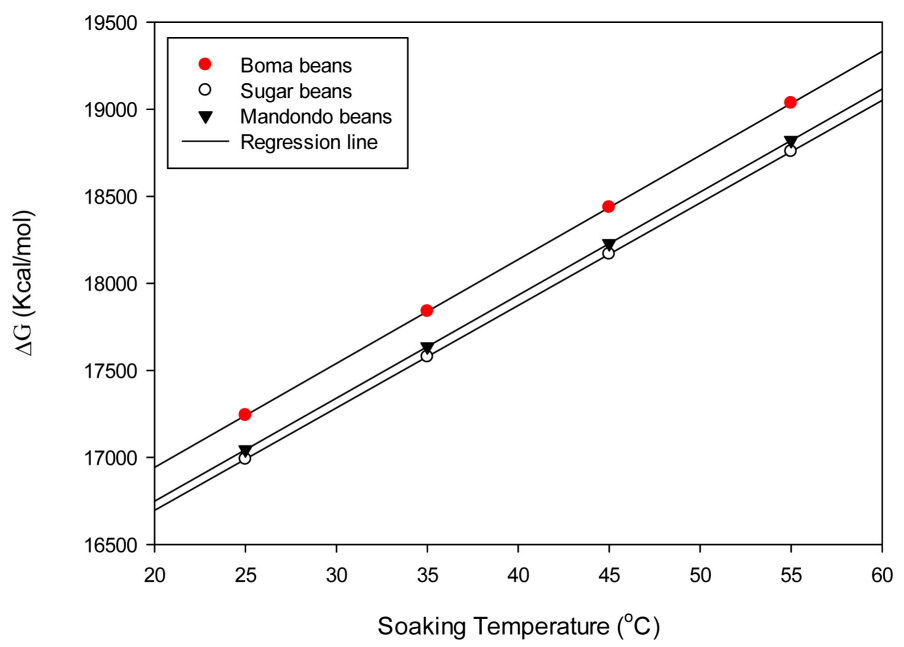

(c)

Figure 3. Thermodynamic variation during soaking (a) enthalpy (b) entropy and (c) Gibbs free energy.

Table 5. Thermodynamic parameters of water absorption.

\begin{tabular}{cccc}
\hline Variety & $E_{a}(\mathrm{kj} / \mathrm{mol})$ & $R^{2}$ & $K_{\text {ref }}$ \\
\hline Boma Beans & 55.84 & 0.974 & 0.592 \\
Sugar beans & 65.25 & 0.975 & 0.919 \\
Mandondo beans & 25.78 & 0.801 & 0.784 \\
\hline
\end{tabular}

hardness pattern can be observed for the beans at different soaking temperatures. These phases which were especially pronounced during soaking at room temperature represent an initial slow softening during the first 30 mins, a subsequent rapid softening then a much slower final softening phase. As can be seen from Figure 4(a), Sugar beans showed the least hardness of the three varieties with a maximum force of 13.5 in its dry state compared to 15.1 and $18.1 \mathrm{~kg}$ for Boma and Mandondo, respectively. After two hours of soaking, hardness of sugar beans reduced by $42 \%$. This seems to corroborate the results from the 


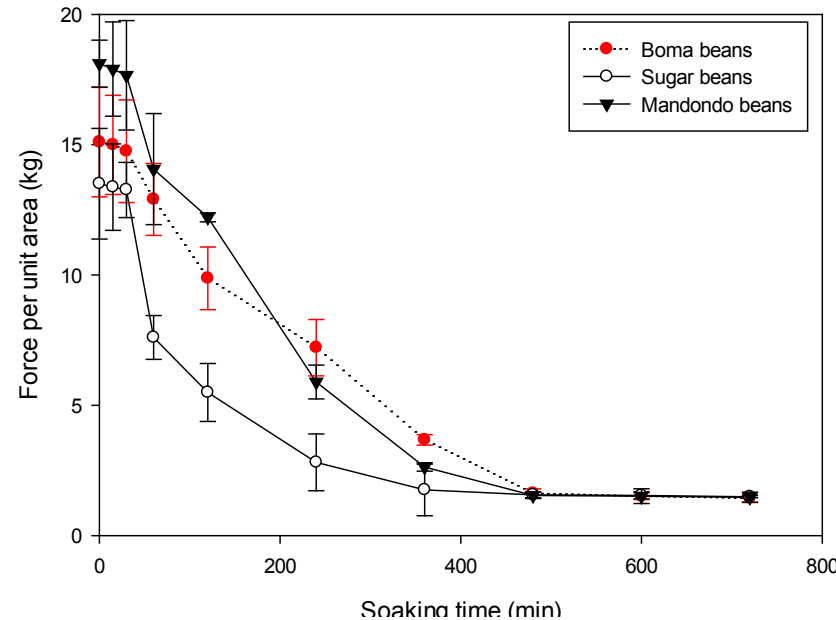

(a)

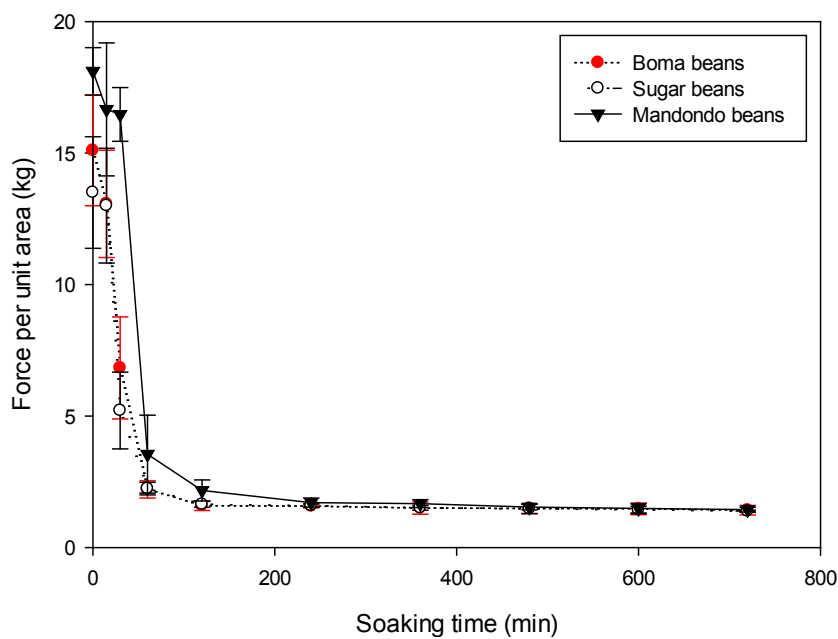

(c)

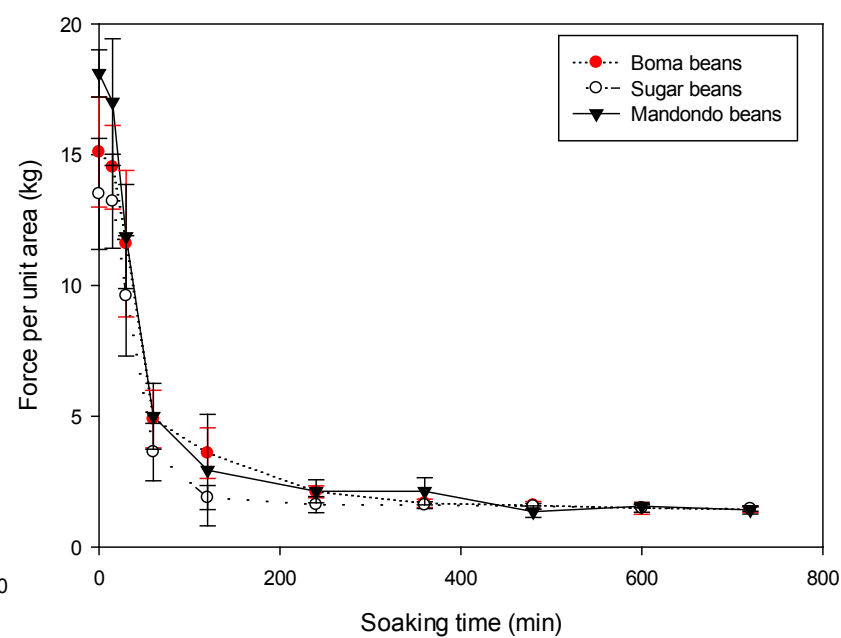

(b)

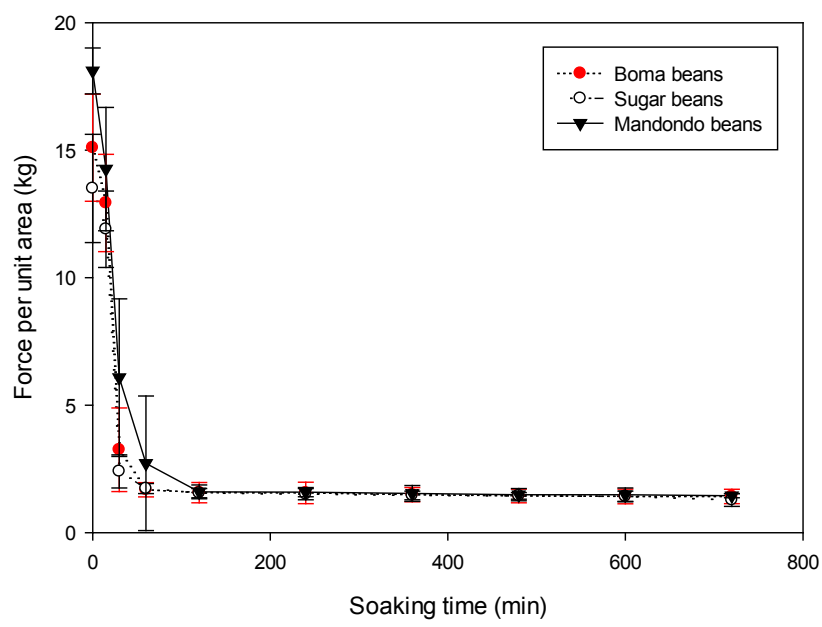

(d)

Figure 4. Bean hardness variation during soaking (a) $25^{\circ} \mathrm{C}$ (b) $35^{\circ} \mathrm{C}$ (c) $45^{\circ} \mathrm{C}$ (d) $55^{\circ} \mathrm{C}$.

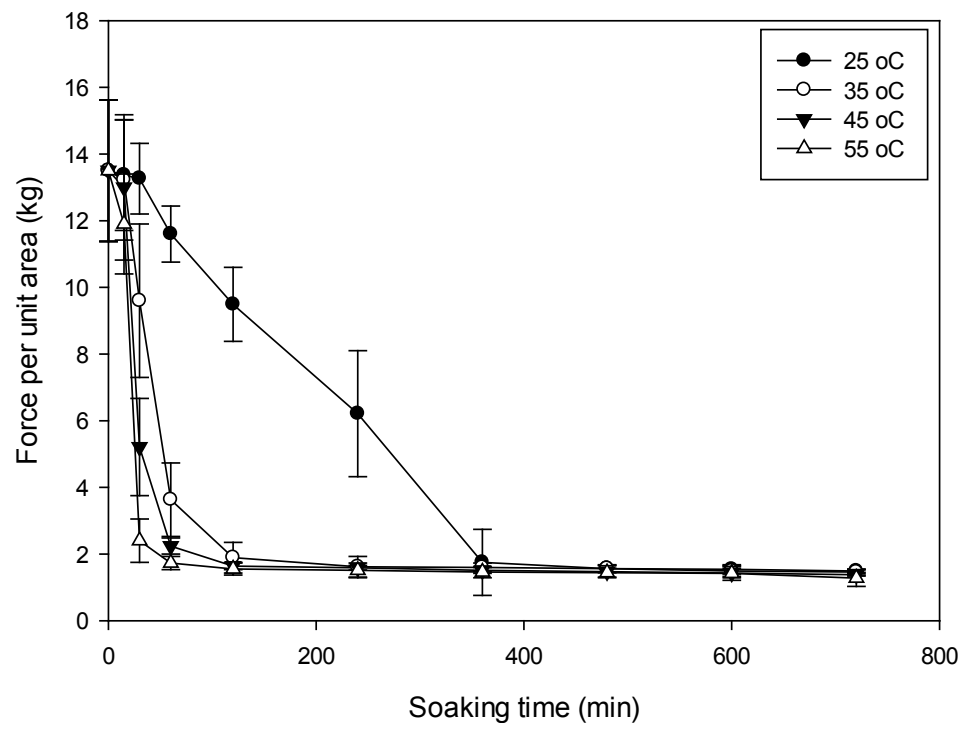

Figure 5. Effect of temperature bean hardness of Sugar beans. 
hydrodynamic characteristics (Section 3.2), which was significantly different from Boma and Mandondo as well as the two parameter Mitscherlich model which indicated that the first phase of water absorption for Sugar beans occurred within 128 mins of soaking. The thermodynamic results which revealed that Sugar beans showed the highest enthalpy change and the greatest energy variation due to bean-water interaction during hydration also seem to support this assertion.

The effect of soaking water temperature on bean hardness, shown in Figure 5 revealed that soaking above room temperature significantly impacted hardness. Although, this difference reduces markedly above $35^{\circ} \mathrm{C}$. Nonetheless, after 360 mins of soaking bean hardness is similar irrespective of the water temperature.

\section{Conclusion}

In this present study, the hydrodynamic characteristics of three Malawian common beans varieties were investigated. Hydration temperature and time had a significant influence $(\mathrm{p}<0.05)$ on the hydration kinetics of the selected common bean varieties. The time required to reach equilibrium water uptake was determined as $10 \pm 1.08$ hours for all bean samples. This equilibrium time reduces to 6 and 4 hours when beans are soaked at $35^{\circ} \mathrm{C}$ and $45^{\circ} \mathrm{C}$. Soaking above $45^{\circ} \mathrm{C}$ did not significantly reduce the equilibrium water uptake except in Sugar beans. The hydrodynamic characteristics were modeled using Peleg model, two-parameter Mitscherlich model and the viscoelastic model. All the models accurately described the water absorption characteristics of the common bean varieties at the selected soaking temperatures. Furthermore, the initial rapid early water absorption was successfully modeled to be between $49.2 \%$ and $99.5 \%$ with the viscoelastic model for the studied varieties. The impact of temperature and time on moisture transfer rate was determined with Arrhenius relation. The activation energies were found to be within $25-65 \mathrm{~kJ} / \mathrm{mol}$. Thermodynamic properties such as enthalpy and entropy change decreased with increasing temperature while Gibbs energy increased with increasing soaking water temperature. Changes in bean hardness were found to be significantly influenced by soaking time and temperature. While it takes 360 mins to reduce bean hardness to less than $20 \%$ at room temperature, the same level of hardness reduction can be achieved in 60 mins during soaking at $55^{\circ} \mathrm{C}$.

\section{Acknowledgements}

The authors gratefully acknowledge the International Fund for Agricultural Development (IFAD) for providing financial assistance through IFAD project grant 2000000974

\section{Conflicts of Interest}

The authors declare no conflicts of interest regarding the publication of this paper. 


\section{References}

[1] Los, F.G.B., Zielinski, A.A.F., Wojeicchowski, J.P., NogueiraIvo, A. and Demiate, M. (2018) Beans (Phaseolus vulgaris L.): Whole Seeds with Complex Chemical Composition. Current Opinion in Food Science, 19, 63-71. https://doi.org/10.1016/j.cofs.2018.01.010

[2] Campos-Vega, R., et al. (2018) Chapter 20 Dry Beans: Processing and Nutritional Effects, in Therapeutic, Probiotic, and Unconventional Foods. In: Grumezescu, A.M. and Holban, A.M., Eds., Academic Press, Cambridge, Massachusetts, 367-386.

[3] Alonso, R., Aguirre, A. and Marzo, F. (2000) Effects of Extrusion and Traditional Processing Methods on Antinutrients and in Vitro Digestibility of Protein and Starch in Faba and Kidney Beans. Food Chemistry, 68, 159-165. https://doi.org/10.1016/S0308-8146(99)00169-7

[4] Alonso, R., Orúe, E. and Marzo, F. (1998) Effects of Extrusion and Conventional Processing Methods on Protein and Antinutritional Factor Contents in Pea Seeds. Food Chemistry, 63, 505-512. https://doi.org/10.1016/S0308-8146(98)00037-5

[5] Anton, A.A., Ross, K.A., Beta, T., Fulcher, R.G. and Arntfield, S.D. (2008) Effect of Pre-Dehulling Treatments on Some Nutritional and Physical Properties of Navy and Pinto Beans (Phaseolus vulgaris L.). LWT-Food Science and Technology, 41, 771-778. https://doi.org/10.1016/j.lwt.2007.05.014

[6] Peleg, M. (1988) An Empirical Model for the Description of Moisture Sorption Curves. Journal of Food Science, 53, 1216-1217.

https://doi.org/10.1111/j.1365-2621.1988.tb13565.x

[7] Wood, J.A. and Harden, S. (2006) A Method to Estimate the Hydration and Swelling Properties of Chickpeas (Cicer arietinum L.). Journal of Food Science, 71, E190-E195. https://doi.org/10.1111/j.1750-3841.2006.00009.x

[8] Yildirim, A., Öner, M.D. and Bayram, M. (2013) Effect of Soaking and Ultrasound Treatments on Texture of Chickpea. Journal of Food Science and Technology, 50, 455-465. https://doi.org/10.1007/s13197-011-0362-8

[9] Sharanagat, V.S., Kansal, V. and Kumar, K. (2016) Modeling the Effect of Temperature on the Hydration Kinetic Whole Moong Grain. Journal of the Saudi Society of Agricultural Sciences, 17, 268-274. https://doi.org/10.1016/j.jssas.2016.05.005

[10] Shafaei, S.M., Masoumi, A.A. and Roshan, H. (2016) Analysis of Water Absorption of Bean and Chickpea during Soaking using Peleg Model. Journal of the Saudi Society of Agricultural Sciences, 15, 135-144. https://doi.org/10.1016/j.jssas.2014.08.003

[11] Deshpande, S.S. and Cheryan, M. (1986) Water Uptake during Cooking of Dry Beans (Phaseolus vulgaris L.). Plant Foods for Human Nutrition, 36, 157-165. https://doi.org/10.1007/BF01092032

[12] Joshi, M., et al. (2010) Water Uptake and Its Impact on the Texture of Lentils (Lens culinaris). Journal of Food Engineering, 100, 61-69. https://doi.org/10.1016/j.jfoodeng.2010.03.028

[13] Shafaei, S.M. and Masoumi, A.A. (2014) Estimating Moisture Absorption Kinetics of Beans during Soaking Using Mathematical Models. Agricultural Engineering International: The CIGR Journal, 16, 8.

[14] Sayar, S., Turhan, M. and Gunasekaran, S. (2001) Analysis of Chickpea Soaking by Simultaneous Water Transfer and Water-Starch Reaction. Journal of Food Engineering, 50, 91-98. https://doi.org/10.1016/S0260-8774(00)00196-5 
[15] Machado, M.F., Oliveira, F.A.R. and Cunha, L.M. (1999) Effect of Milk Fat and Total Solids Concentration on the Kinetics of Moisture Uptake by Ready-to-Eat Breakfast Cereal. International Journal of Food Science \& Technology, 34, 47-57. https://doi.org/10.1046/j.1365-2621.1999.00238.x

[16] Espert, A., Vilaplana, F. and Karlsson, S. (2004) Comparison of Water Absorption in Natural Cellulosic Fibres from Wood and One-Year Crops in Polypropylene Composites and Its Influence on Their Mechanical Properties. Composites Part A: Applied Science and Manufacturing, 35, 1267-1276. https://doi.org/10.1016/j.compositesa.2004.04.004

[17] de F́tima Machado, M., et al. (1998) Kinetics of Moisture Uptake and Soluble-Solids Loss by Puffed Breakfast Cereals Immersed in Water. International Journal of Food Science \& Technology, 33, 225-237.

[18] Khazaei, J. and Mohammadi, N. (2009) Effect of Temperature on Hydration Kinetics of Sesame Seeds (Sesamum indicum L.). Journal of Food Engineering, 91, 542-552. https://doi.org/10.1016/j.jfoodeng.2008.10.010

[19] McWatters, K.H., Chinnan, M.S., Phillips, R.D., Beuchat, L.R., Reid, L.B. and Mensa-Wilmot, Y.M. (2002) Functional, Nutritional, Mycological, and Akara-Making Properties of Stored Cowpea Meal. Journal of Food Science, 67, 2229-2234. https://doi.org/10.1111/j.1365-2621.2002.tb09532.x

[20] AOAC (2005) Official Methods of Analysis. Association of Official Analytical Chemists, Arlington.

[21] Eknayake, S., Jansz, E.R. and Nair, B.M. (1999) Proximate Composition, Mineral and Amino Acid Content of Mature Canavalia gladiata Seeds. Food Chemistry, 66, 115-119. https://doi.org/10.1016/S0308-8146(99)00041-2

[22] Turhan, M., Sayar, S. and Gunasekaran, S. (2002) Application of Peleg Model to Study Water Absorption in Chickpea during Soaking. Journal of Food Engineering, 53, 153-159. https://doi.org/10.1016/S0260-8774(01)00152-2

[23] Ratkowsky, D.A. (1990) Handbook of Nonlinear Regression Models. Marcel Dekker Inc., New York.

[24] Gowen, A., Abu-Ghannam, N. and FriasaJ.Oliveir, J. (2007) Influence of Pre-Blanching on the Water Absorption Kinetics of Soybeans. Journal of Food Engineering, 78, 965-971. https://doi.org/10.1016/j.jfoodeng.2005.12.009

[25] Miano, A.C., Sabadoti, V.D. and Augusto, P.E.D. (2018) Enhancing the Hydration Process of Common Beans by Ultrasound and High Temperatures: Impact on Cooking and Thermodynamic Properties. Journal of Food Engineering, 225, 53-61. https://doi.org/10.1016/j.jfoodeng.2018.01.015

[26] dos Santos Siqueira, B., Vianello, R.P., Fernandes, K.F. and Bassinell, P.Z. (2013) Hardness of Carioca Beans (Phaseolus vulgaris L.) as Affected by Cooking Methods. LWT-Food Science and Technology, 54, 13-17. https://doi.org/10.1016/j.lwt.2013.05.019

[27] Revilla, I. and Vivar-Quintana, A.M. (2008) Effect of Canning Process on Texture of Faba Beans (Vicia Faba). Food Chemistry, 106, 310-314. https://doi.org/10.1016/j.foodchem.2007.02.046

[28] Ai, Y., Cichy, K.A., Harte, J.B., Kelly, J.D. and Perry, K.W. (2016) Effects of Extrusion Cooking on the Chemical Composition and Functional Properties of Dry Common Bean Powders. Food Chemistry, 211, 538-545. https://doi.org/10.1016/j.foodchem.2016.05.095

[29] de Almeida Costa, G.E., da Silva Queiroz-Monici, K., Reis, S.M.P.M. and de Olivei- 
ra, A.C. (2006) Chemical Composition, Dietary Fibre and Resistant Starch Contents of Raw and Cooked Pea, Common Bean, Chickpea and Lentil Legumes. Food Chemistry, 94, 327-330. https://doi.org/10.1016/j.foodchem.2004.11.020

[30] Azaza, M.S., Wassim, K., Mensi, F., Abdelmouleh, A., Brini, B. and Kraïem, M.M. (2009) Evaluation of Faba Beans (Vicia faba L. var. minuta) as a Replacement for Soybean Meal in Practical Diets of Juvenile Nile Tilapia Oreochromis niloticus. Aquaculture, 287, 174-179. https://doi.org/10.1016/j.aquaculture.2008.10.007

[31] Hsu, K.H. (1983) A Diffusion Model with a Concentration-Dependent Diffusion Coefficient for Describing Water Movement in Legumes During Soaking. Journal of Food Science, 48, 618-622. https://doi.org/10.1111/j.1365-2621.1983.tb10803.x

[32] Quast, D.G. and da, S.D. (1977) Temperature Dependence of Hydration Rate and Effect of Hydration on the Cooking Rate of Dry Legumes. Journal of Food Science, 42, 1299-1303. https://doi.org/10.1111/j.1365-2621.1977.tb14482.x

[33] Costa, R., Fusco, F. and Gândara, J.F.M. (2018) Mass Transfer Dynamics in Soaking of Chickpea. Journal of Food Engineering, 227, 42-50.

https://doi.org/10.1016/j.jfoodeng.2018.02.004

[34] Montanuci, F.D., de Matos Jorge, L.M. and Jorge, R.M.M. (2013) Kinetic, Thermodynamic Properties, and Optimization of Barley Hydration. Food Science and Technology (Campinas), 33, 690-698. https://doi.org/10.1590/S0101-20612013000400014

[35] Abu-Ghannam, N. and McKenna, B. (1997) Hydration Kinetics of Red Kidney Beans (Phaseolus vulgaris L.). Journal of Food Science, 62, 520-523. https://doi.org/10.1111/j.1365-2621.1997.tb04420.x

[36] Corzo, O. and Bracho, N. (2006) Application of Peleg Model to Study Mass Transfer during Osmotic Dehydration of Sardine Sheets. Journal of Food Engineering, 75, 535-541. https://doi.org/10.1016/j.jfoodeng.2005.05.001

[37] Kinyanjui, P.K., Njoroge, D.M., Makokha, A.O., Christiaens, S., Ndaka, D.S., et al. (2015) Hydration Properties and Texture Fingerprints of Easy- and Hard-to-Cook Bean Varieties. Food Science \& Nutrition, 3, 39-47. https://doi.org/10.1002/fsn3.188

[38] Miano, A.C. and Augusto, P.E.D. (2015) From the Sigmoidal to the Downward Concave Shape Behavior during the Hydration of Grains: Effect of the Initial Moisture Content on Adzuki Beans (Vigna angularis). Food and Bioproducts Processing, 96, 43-51. https://doi.org/10.1016/j.fbp.2015.06.007

[39] Calzetta Resio, A.N., Aguerre, R.J. and Suarez, C. (2005) Analysis of Simultaneous Water Absorption and Water-Starch Reaction during Soaking of Amaranth Grain. Journal of Food Engineering, 68, 265-270.

https://doi.org/10.1016/j.jfoodeng.2004.05.043 